\title{
CONSIDERATIONS REGARDING BUILDING MOTOR SKILLS SPECIFIC TO MILITARY PHYSICAL ACTIVITIES
}

\author{
Col.Adv.Instr. Alin PELMUȘ, PhD*
}

\begin{abstract}
In its first part, the article addresses issues related to the concept, characteristics and typology of motor skills. Subsequently, some evaluations related to the mechanism of building motor skills are revealed and their stages highlighted, insisting on the methodical ones. Throughout the article, opinions are also expressed about the complexity of the motor skills training process applicable in the military system and their special importance in combat training.
\end{abstract}

Keywords: motor skills; military training; formation; consolidation; improvement; complexity.

The sphere of skills is not limited only to motor activity. Most of the skills we use on a daily basis include elements performed on the background of the operations previously formed in school or family. In everyday human activities we encounter intellectual, sensory, work, artistic, sports skills etc.

Therefore, skills are ways of action, execution techniques in various activities that, consolidated and improved through multiple repetitions, become automated components of these activities. Military training is the process in which a lot of skills are needed, the motor ones occupying a special place.

Regarding motor skills, their problem is widely treated in the literature, being devoted to numerous studies. In order to elucidate the problem of motor skills, there are still difficulties due to their treatment from several points of view, nuanced and interpreted according to the authors' specialty, as follows: physiological, psychological, pedagogical, sports or physical education theory.

Motor skills are human motor actions, which occur and are formed throughout individual life, through conscious and systematic exercise. They are formed either as a result of human evolution or as a result of participation in organized training processes, as is military physical education. Unlike especially organized training processes (physical education, sports training, military training, etc.), in life practice can often acquire wrong motor skills as a mechanism of execution, which are subsequently difficult to remedy.

\footnotetext{
*"Carol I" National Defence University e-mail:pelmusalin@yahoo.com
}

The formation of motor skills is a conditioned reflex activity, based on the repetition of the interaction between different excitations (kinesthetic, visual, auditory, etc.) transmitted to the cerebral cortex in the same order and with the same intensity. The reflexes thus acquired unify the components of the action, establishing a chain of multiple and complex connections between analyzers, sensitive and motor areas of the cortex, systematically organized by means of the second signaling system.

From the multitude of definitions of motor skills encountered in the literature, Whiting's approach seemed to me the most conclusive and complete: "... a series of complex and intentional motor actions, involving a chain of sensory, central and motor mechanisms that by the learning process has become organized and coordinated, so that they allow the achievement of objectives, with maximum security".

From this point of view but also from the considerations of most authors, it is found that motor skills are seen as behaviors aimed at achieving certain goals through minimal energy expenditure and can be acquired only after practice, which leads to increased perfection of the movements performed, their realization with ease and precision.

In the superior phase of acquiring motor skills, when we can speak of perfection (or "motor excellence", a term encountered in the field of physical education and sports), certain complex sensations are formed, which are expressively called "senses" (we can talk about the sense of the ball, the sense of the racket or paddle, the sense of water or snow, the sense of the bar, etc.) $)^{2}$. 
Therefore, motor skills are a process that includes both practice and other means of a complex psycho-pedagogical nature. Psychologist Mihai Epuran highlights the following main characteristics ofmotor skills: they are part of human voluntary conduct, gaining ease and accuracy based on voluntary effort; they are included in various "movement families", belonging to clearly defined motor behaviors; they are integrated into "movement systems" as simpler units; they act as systems that have corrective feedback, every time when in their execution inaccuracies intervene; they imply an increased capacity for fine differentiation of movements, based on sensory-perceptual information; even if they are executed in variable conditions, they have a relative stability, which determines their imposition in the motor behavior (it is important that the skills are formed correctly from the beginning, as the subsequent correction is very difficult); they cover all the particularities of the subjects who perform them, so that, at higher levels of learning and application, one can discuss "style"; their building process is conditioned by certain objective and subjective factors (skills, motivation, attitude, ambience and educational conditions, self-esteem capacity, etc. $)^{3}$.

In the literature we find many criteria according to which the types or categories of motor skills are established. From the multitude of criteria, for this article we chose the following:

a) Depending on the level of automation:

- basic motor skills. They are fully automated, being made up of a chain of phasic movements, which are repeated in the same sequence (cyclic movements such as walking, running, swimming, cycling, etc.);

- complex motor skills. These are partially automated, consisting of basic skills and some nonautomated or incompletely automated movements (skills in sports games and other branches or acyclic sports such as gymnastics, combat sports, jumping, throwing, etc.);

b) Depending on the finality of use:

- basic and utilitarian-applied motor skills - are used mainly in everyday life in human development, but also for the practice of sports / application tests (walking, running, jumping, throwing, catching, crawling, climbing, escalation, traction-pushing, transport weights / objects etc.);

- motor skills specific to sports branches (specific technical elements and procedures). c) Depending on the level of participation of the nervous system in their formation and capitalization:

- proper motor skills, which are performed very often (dynamic stereotypes, such as elements and technical procedures specific to gymnastics, skating, platform jumping, etc.);

- perceptual-motor skills, in which the environment influences their formation and capitalization (specific skills of skiing, „oina”, baseball, shooting, etc.);

- intelligent-motor skills, in which the competing partners and opponents influence their formation and, especially, their capitalization (skills specific to sports games, combat sports, fencing, etc. $)^{4}$.

In the military training process, the mentioned categories of motor skills are learned in the activity of physical education and sports, but the complexity of military actions involves the formation of a wide range of skills, such as: basic motor skills and utility-applications adapted to the battlefield (march, running in various terrain, throwing grenades, crawling with weapons and equipment, climbing various obstacles in the field, climbing steep slopes, transporting specific equipment and materials or injured people, jumping in length, depth, height, etc.) ; motor skills specific to military branches and specialties; perceptual-motor skills (firing with different types of weapons being a skill that must be acquired by all soldiers); intelligentmotor skills (we meet them, mainly, in the training process for close combat, with or without the weapons and equipment) etc.

Therefore, we can say that motor skills are the qualitative characteristics of learned motor acts and actions. The formation of motor skills (in some cases reformation or reconstruction) is the fundamental goal of physical education, sports training, physical therapy or other socioprofessional fields, including, as we have seen, obviously military training.

The main physiological mechanisms and processes involved in the formation and consolidation of motor skills are the phenomena of development and strengthening of temporary connections, irradiation, concentration and induction of fundamental nervous processes (excitation and inhibition). Following the continuous organization and systematization of 
nervous processes, a dynamic stereotype is formed. The leader's instructions and assessments during the exercises complete and clarify the sensations, perceptions and representations of the soldier, the knowledge and the image about the action, mobilize him and direct his effort to achieve the most accurate executions.

The building and consolidation of motor skills is done gradually, through numerous repetitions. The process of forming and perfecting the dynamic stereotype that underlies motor skills goes through several stages. The time required to develop this stereotype and each stage differs from individual to individual or from one motor action to another, depending on: the complexity of the movements that are part of the skill to be learned; previous motor experience of the performer; the level of development of the required motor qualities; the level of development of coordination capacity; the interest, the motivation of the participants in the respective action, which determines the concentration of attention, the conscious-active participation, the mobilization, all supported by the effort of will.

Regarding the stages of motor skills formation, the literature in the field presents their number and name differently, depending on the field that treats them, even if, analyzing them carefully, these all lead to the same conclusions. In this sense, I chose to briefly present, without describing them, the psychological and physiological stages of the formation of motor skills and, in more detail, the stages from a methodological point of view.

Thus, psychology presents four stages (phases) of the formation of motor skills, as follows: the initial stage, in which the performer orients himself and becomes familiar with the action; the stage of acquiring each element of the action; the stage of unifying the elements of the action acquired separately; the automation stage. From a physiological point of view, in the formation and consolidation of motor skills, we distinguish the following stages: that of unnecessary movements that are performed in a rude manner, without coordination; the stage of movements performed in accordance with the purpose of the action, but through excessive muscle contractions; the stage of actual acquisition, fixation and stabilization of motor skills 5 .
According to the methodology of physical education and sports, motor learning is achieved through the following stages with their main objectives:

- the initiation stage ("primary learning") laying the technical foundations for the execution of that movement. The main specific objectives of this stage are: the formation, through explanation and demonstration, of a representation on the skill to be learned; formation of a cursive rhythm of execution; disassembly of that skill, if possible and if necessary, into component elements that are practiced analytically separately; the prevention of typical execution errors or their correction. Predominant for this initial stage is the volume of physical effort;

- the stage of consolidating the motor skill, which has as main objectives the following: the completion of the technique of execution of the movement, in accordance with the optimal spatiotemporal characteristics; creating the premises for the execution of the skill in various conditions, by strengthening the temporal ties, as a result of the fact that it is practiced in relatively and predominantly constant/standardized conditions; correction, with priority, of possible individual execution errors. It is the phase of increasing the role of the intensity of the physical effort, of the control or self-control of the execution level;

- the stage of improving the motor skill. The main objectives in this stage are: to increase the number of variants of execution of the respective skill, by performing the specific technical procedures at a higher level; practicing it in conditions as varied as possible and similar to those encountered in real life, mainly in competitive sports activities; the inclusion of the respective skill in a series of other motor skills and the execution of the resulting combinations with ease, fluency, precision and efficiency. The specificity of this stage is given by the complexity of the physical effort, which intervenes with a substantial contribution to the achievement of the proposed finalities ${ }^{6}$.

Within the process of forming motor skills, especially those with military specifics, transfer phenomena are identified, the previously acquired skills influencing favorably or unfavorably the elaboration of new ones. The favorable or positive influence is called transfer, and the unfavorable or braking influence is called interference (negative transfer). 
The transfer occurs when there are common or similar elements between the skills previously formed and those being acquired. The transfer cannot be limited to the simple mechanical association between the identical elements of the old and new skills, but must be the result of a process of analysis and synthesis, of conscious generalization of the motor experience. In order to favor this process, the military must be helped by explanations, as precisely as possible, able to highlight the similarities and differences, to outline exactly the structure, nature and characteristics of the elements that make up the new action.

With regard to the negative transfer, the "loan" overlaps, replacing a new non-acquired element with a known element with another motor structure. In this case, the process of developing the new skill is difficult, slowed down. Negative transfer or interference may also occur from a new, consolidating asset to an old one that has not been sufficiently fixed.

Given that we are dealing with the absence of physical exercises or their repetition at long intervals, there is certainly a weakening of motor skills, a loss of accuracy and ease in performing component movements. This phenomenon is due to the inhibition that acts in the sense of extinguishing the temporary connections, the motor skills being conditioned reflexes with a lower degree of stability.

Regarding the skills formed against the background of defence reflexes, which abound in the military environment (skiing, swimming, combat sports, etc.), cases of forgetfulness or complete loss are very rare, even impossible. This aspect is explained in terms of the fact that the second signalling system (the basis for the building of verbal and logical thinking about the world around, the imagination in human memory) has the opportunity to update temporary connections in the absence of practical executions. Although the character of automation is lost, under the control and guidance of consciousness, the movements can be performed with relative ease and precision.

As we mentioned, in the military environment, basic motor skills such as walking, running, jumping, throwing, weightlifting, climbing, etc. are transformed into specific utilitarian-applicative skills, as follows: crossing the different paths with obstacles; lifting and transporting weights (materials and equipment); close combat; crossing watercourses with military equipment and weapons; crossing mountain slopes, winter or summer, with and without skis and other specific equipment, etc.

In this manner, combat training sets its actions on the results obtained from the instructional process of military physical education and sports, and this activity, in turn, studies the structures of all training actions, the nature and duration of efforts to be made, the environment and place of missions in which the military is involved.

In conclusion, motor skills, aptitudes and knowledge are acquired following an extensive training process oriented and scientifically conducted to achieve the proposed objectives. The development of a vast baggage of motor skills and mental abilities, in accordance with the requirements of modern military conflicts, is becoming increasingly important. The mental stress caused by the multitude of demanding factors specific to the operational environment, as well as the decrease in physical effort capacity cannot be removed, but their effects can certainly be reduced by forming skills necessary to perform the full range of missions in which the military is engaged. In other words, the success of the forces engaged in military conflicts depends to a large extent on the value of the motor performance and the level of mental qualities of the personnel serving the armament, equipment and combat technique. The aptitude-motor level represents the essential element of the operational value of the military structures in the composition of the army.

\section{NOTES:}

1 A. Dragnea et al., Physical education and sports theory and didactics, FEST Publishing House, Bucharest, 2006, p. 130.

2 Gh. Cârstea, Theory and methodology of physical education and sports, AN-DA Publishing House, Bucharest, 2000, p. 17.

3 https://pregatirefizica.wordpress.com/2017/06/13/ deprinderile-motrice, accessed on 08.05.2021.

4 Gh. Cârstea, op.cit., pp. 71-72.

$5 \mathrm{http}$ //educatie-fizica.ro/invatarea-motrica-formareadeprinderilor-motrice, accessed on 08.05.2021.

6 Gh. Cârstea, op.cit., pp. 70-71.

\section{REFERENCES}

Bota A., Kinesiology, Didactic and Pedagogical Publishing House, R.A., Bucharest, 2007. 
Cârstea Gh., Theory and methodology of physical education and sports, AN-DA Publishing House, Bucharest, 2000.

Dragnea A. et.al., Physical education and sports - theory and didactics, FEST Publishing House, Bucharest, 2006.

Epuran M., Motor skills and psychism in bodily activities, FEST Publishing House, Bucharest, 2011.
Pelmuș A.D., Development of the motor capacity of the military personnel, Publishing House of the Army Editorial Technical Center, Bucharest, 2021. https://pregatirefizica.wordpress.com/2017/06 /13/deprinderile-motrice

http://educatie-fizica.ro/invatarea-motricaformarea-deprinderilor-motrice

https://www.academia.edu/17334296/Invata rea_deprinderilor_motrice 